\title{
Impact of Affective Factors on Senior High School Students with Low English Reading Ability
}

\author{
Chubai Liu ${ }^{1} \&$ Xinjie Luo ${ }^{1}$ \\ ${ }^{1}$ Foreign Languages College, Jiangxi Normal University, China \\ Correspondence: Chubai Liu, Foreign Languages College, Jiangxi Normal University, Yaohu Campus, 99 \\ Ziyang road, Nanchang, Jiangxi, 330022, China.
}

Received: October 27, 2021

Accepted: November 16, 2021

Online Published: November 24, 2021

doi: 10.5539/elt.v14n12p91

URL: https://doi.org/10.5539/elt.v14n12p91

\begin{abstract}
In 2017, the Ministry of Education promulgated the General High School English Curriculum Standards (2017 Edition), which stressed the importance of affective factors in English learning. This study uses a combination of qualitative and quantitative research methods such as student questionnaires and interviews to explore the motivational function of affective factors and its negative influence upon English reading of 80 students with low English reading ability in a high school in Jiujiang. The results of the study show that reading anxiety is common among high school students, the internal motivation for English reading is weak and the external motivation is strong, the self-efficacy of reading is not clear and firm. The study further found that the great academic pressure and high school students' self-awareness which are subject to external environment, language and other factors cause high school students' anxiety, the international social environment and examination system have a large impact on high school student' external motivation. In order to improve the English reading ability of high school students, this research tries to make corresponding suggestions for teachers, students and other aspects from the perspective of affective factors. As for the English teachers, they should set up diversified activities and increase the interest of teaching content in order to promote emotions with knowledge. As for the students, they should clarify their tasks to enhance learning motivation. The school should set up mental health courses and psychological counseling room and provide psychological training for teachers. Then, parents should try to communicate with students and learn to ask for help rather than paying too much attention to students' performance.
\end{abstract}

Keywords: affective factors, high school students, reading teaching, low English reading ability

\section{Introduction}

Under the background of globalization, in order to seek a higher level of development, developed and developing countries continue to train professionals to communicate with other countries in political, economic, cultural and other aspects. English, as a universal lingua franca, is widely used in all fields of people's life, and its importance is becoming more and more prominent.

English reading articles gather vocabulary, sentences, grammar, style, cultural background knowledge and other aspects in one. In English examination, the question type of English reading comprehension always accounts for the largest proportion. It is obvious to see the importance of reading in English. The five language skills of listening, speaking, reading, writing and translation influence each other, and the improvement of reading ability can promote the development of other skills accordingly. However, in the actual process of English reading, students are unable to understand the main idea of the passage and fail to complete the reading task on time. Therefore, it is urgent to improve students' English reading level.

This study studies the influence of affective factors on English reading of senior high school students and analyzes the influence factors of affective factors on English reading of senior high school students with low English reading ability. It also puts forward some suggestions on how to overcome the English reading obstacles of senior high school students from affective factors, hoping to get some enlightenment, which will enrich the theory of English reading teaching and learning to a certain extent. This study has certain practical significance for both teachers and students. As far as students are concerned, this study is helpful for students to find out the causes of their own English reading disorders and arouse students' attention to English reading emotion, so as to improve students' English reading ability to a certain extent. As far as teachers are concerned, this study helps 
teachers to find out the causes of students' emotional factors on English reading difficulties, and has a certain positive significance for teachers to optimize the teaching of English reading.

\section{Literature Review}

\subsection{Difference between English Dyslexia and Low English Reading Ability}

Dyslexia was proposed by Morgan (1896). It refers to the phenomenon that a learner's reading is hindered by temporary lack of ability and stuck in the process of mutual transformation between written language and oral language. Oxford (1996) pointed out that dyslexia is a disease in children with dyslexia because the left hemisphere of the brain is not fully developed and the level of information processing in the two hemispheres of the brain is not coordinated. Thus it can be seen that in early foreign countries, most of the subjects who paid attention to dyslexia in English-speaking countries were medical experts or neuroscientists, and the research focused on the pathological factors that caused dyslexia.

$\mathrm{Hu}$ (1998) believed that reading ability is a kind of comprehensive ability, the ability of reading comprehension and the ability shown through the reading process. Foreign scholar West Michael pointed out that reading ability is not limited to a single language, the improvement of reading ability of one language can improve the reading level of another language. The two scholars expounded reading ability from different angles, and comprehensively revealed the essence of reading ability, that is, reading ability is a kind of individual psychological characteristic and a comprehensive ability shown through the reading process, which is not limited to one language and can be transferred between different languages.

The difference between English dyslexia and low English reading ability is that the former is used to describe those who have reading disorder caused by physical or pathological reasons, while English reading ability is a kind of comprehensive ability. This study focus on the impact of affective factors on learners' English reading ability in the process of reading.

\subsection{The Definition of Affective Factors}

In language teaching, emotion refers to the learners' feelings, emotions, attitudes and so on. Alpert (1960) pointed out that emotion is all the factors related to language teaching, which can affect students' learning attitude, may promote students' learning, stimulate students' initiative, and may also lead to negative learning emotions. Arnold (1999) classifies affective factors in foreign language teaching into two categories: one is learners' individual factors, including self-esteem, anxiety, inhibition, personality and motivation, and the other is emotional factors between learners, including empathy, classroom communication, cross-cultural awareness. This study mainly studies three factors: reading motivation, reading anxiety and self-efficacy in reading.

(1) Reading Motivation

Motivation can cause and maintain the activity of the individual, and make the activity toward a certain goal of the internal motivation. Motivation is a very important factor in second language acquisition. This study focuses on the influence of students' motivation on English reading. In other words, this study mainly studies the influence of students' internal motivation and extrinsic motivation on English reading ability.

\section{(2) Reading Anxiety}

Anxiety is that individuals worry that they can not achieve a certain goal or can not overcome obstacles, resulting in self-esteem and self-confidence frustration or increased sense of failure, guilt, the formation of a nervous psychological state. Proper anxiety can stimulate students' learning motivation, while excessive anxiety can lead to students' nervousness. The reading anxiety studied in this study mainly refers to the influence of students' classroom anxiety and test anxiety on English reading disorder.

\section{(3) Self-efficacy in Reading}

Self-efficacy refers to an individual's belief, judgment or feeling about his or her imminent behavior. Self-efficacy is one of the important factors that affect learners' learning performance. This study focuses on the effects of students' persistence, effort and ability self-efficacy on English reading.

\subsection{Previous Studies on English Reading Ability}

\subsubsection{Research on English Reading Ability Abroad}

When studying English reading ability in countries that use English as a second language, they mainly study the current situation of students' English reading difficulties through questionnaires, interviews and other scientific research methods. Barfield (1999) conducted a survey of freshmen of non-English majors and found that different reading difficulty levels lead to different causes of English reading difficulties. 
Foreign researchers have also tried how to solve English learners with low English reading ability. Some researchers will point out ways to improve English learners with reading difficulties based on experience or theory. For example, Torgesen (2002) put forward some teaching suggestions to prevent reading difficulties based on the reading knowledge and newly learned reading knowledge in the past 20 years. Alqarni (2015) discussed the advantages of cooperative reading and holds that cooperative reading can help students improve their English reading ability. As a result of paying attention to the obstacles at the knowledge level of English reading, foreign scholars mainly emphasize the solutions at the knowledge level on how to solve the English reading disorders.

\subsubsection{Research on Low English Reading Ability in China}

Cui and Feng (2008) mainly studied the influence of culture on English reading and emphasize that culture is also an important factor affecting English reading through vocabulary, idioms, allusions and text background. Through a questionnaire, Hao (2011) explored the influence of thinking style on senior high school students' English reading comprehension, and analyzes the relationship between thinking and gender, reading materials and reading proficiency. Fan and Fu (2012) mainly analyzed the causes of students' English reading difficluties from two aspects, the present situation of teachers' teaching and students' learning, and put forward some improvement methods to improve students' reading ability.

$\mathrm{Su}$ (2010) analyzed the relationship between the level of English reading comprehension and the model of information structure: the task of primary English reading is to obtain linear information, the task of intermediate English reading is to obtain cross-information, the task of advanced English reading is to obtain network information. Based on cohesion theory, Duan and Wu (2012) pointed out that students' attention to cohesive words such as reference, substitution, ellipsis and conjunction in English reading is conducive to a better understanding of textual knowledge.

\subsection{Previous Studies on Affective Factors}

\subsubsection{Research on Affective Factors Abroad}

Foreign researchers focus on affective factors and language learning. Krashen (1985) regarded "affective filtering" as a key factor in second language acquisition. His "Affective Filtering Hypothesis" illustrated the relationship between language learners' motivation, self-confidence, anxiety and other affective factors and language learning. Krashen believed that motivation, self-confidence and anxiety are the main affective factors that affect language acquisition. Whether students' learning motivation and purpose are clear or not directly affects the learning effect. Rogers (1994) put forward the educational idea of student-centered theory, which holds that in the process of education, teachers should highlight the status and role of emotion and solve emotional problems. form a new teaching model and take emotion as the basic driving force of teaching activities.

Brown (2009) believed that affective factors play a decisive role in second language learning, and unsuccessful foreign language learning can be attributed to a variety of affective disorders. O'Malley and Chamot (1990) divided learning strategies into metacognition, cognitive strategies and affective strategies according to Anderson's cognitive theoretical framework. Affective strategies refer to the methods that learners use to regulate and manage emotions and emotions. In foreign language learning, affective strategies can regulate emotion, motivation and attitude, which is no less important than cognitive and metacognitive strategies.

\subsubsection{Research on Affective Factors in China}

Zhang (1985) believed that emotion has two major functions in foreign language teaching: dynamic function and signal function. Dynamic function can awaken students' learning motivation, coordinate various cognitive activities and make them balanced and harmonious. The signal function can promote emotion, together with language and body language, into language input and output signals, thus making understanding and expression more appropriate. Zhou (2009) believed that the use of emotional factors in English classroom teaching is conducive to the all-round development of students and improve the quality of English teaching. Zhan (2015) studied the causes of English reading anxiety and put forward some methods to alleviate English reading anxiety.

To sum up, researchers at home and abroad attach importance to the study of English dyslexia and affective factors, and the domestic research trend has gradually shifted from the study of students' knowledge barriers to the combination of students' knowledge barriers and non-knowledge barriers. 


\section{Methodology}

\subsection{Research Questions}

The present study attempts to find out the answer to the following questions:

(1) What is the current situation of English reading ability in senior high school students?

(2) What is the influence of affective factors on low English ability of senior high school students?

(3) How to deal with the influence of affective factors on low English ability of senior high school students?

\subsection{Participants}

The subjects of this survey came from the second-year students who had low English reading ability in a middle school in Jiujiang. A total of 80 questionnaires were distributed to the students, some missing and randomly filled questionnaires were eliminated, and 78 valid questionnaires were recovered. The effective recovery rate of the questionnaire is about $97.5 \%$, three students from two class and a total of 6 students were interviewed. After obtaining the consent of the students, the whole interview process was recorded in order to collate the interview results later.

After a year of study, the students in the second year of senior high school have adapted to the teaching methods, teaching style, living environment, school management and so on. The level of students' knowledge is relatively stable which can ensure students to fill out questionnaires and conduct interviews smoothly.

\subsection{Instruments}

\subsubsection{Anxiety Questionnaire}

The questionnaire draws lessons from the foreign language classroom anxiety scale (Horwitz, 1986), the English learning motivation scale (Gardner, 1972) and the English self-efficacy scale (Meng, 2011). Because some of the questions in the questionnaire are not related to the content of this study, this questionnaire adopts the above three questionnaires and combines the self-designed questions.

The questionnaire consists of two parts. The first part is the basic information of students, including gender and grade. The second part is the questionnaire, a total of 29 questions. The scale is statistically analyzed according to the five Likert scale, in which 1 represents strongly disagree, 2 disagree, 3 uncertain, 4 basicallly agree, 5 represents strongly agree. Students are required to choose an option according to their actual situation.

\subsubsection{Interview}

In the outline of the students' semi-structured interview, the main purpose of the interview is to make up for the deficiency of the students' questionnaire and to understand the influence of emotional factors on students with low English reading ability from more aspects. The interview mainly includes the following questions:

1) In which part of English reading do you lose the most points?

2) After the test, do you reflect on the reading section where you lost a lot of points and find out the reason?

3) Which of the following options do you think should be considered in your reflection? Please rank them in order:
A. Your reading ability
B. Your effort
C. Difficulty of reading task
D. Good or bad luck
E. Physical and mental condition
F. External environment

4) What other reasons do you think influence your reading besides the lack of relevant English knowledge?

\subsection{Data Collection and Analysis}

Data collected from the questionnaires are analyzed by SPSS19.0

\section{Results and Discussion of the Research}

\subsection{Results and Analysis of Questionnaires}

The first part of the student questionnaire is the basic information, including a brief introduction to the survey, as well as the gender and grade of students. As this survey only involves students in the second year of senior high school, it will not analyze the factor of grade here. 
Table 1. Basic Information of the Questionnaire

Gender

\begin{tabular}{llllll}
\hline & & Frequency & Percent & Effective Percent & Cumulative Percent \\
\hline Available & 1 & 44 & 56.4 & 56.4 & 56.4 \\
& 2 & 34 & 43.6 & 43.6 & 100.0 \\
& Total & 78 & 100.0 & 100.0 & \\
\hline
\end{tabular}

As can be seen from Table 1, the valid subjects of this survey are 78 students, including 44 girls, numbered 1 , accounting for $56.4 \%$, and 34 boys, numbered 2 , accounting for $43.6 \%$. The survey data show that there are 10 more girls than boys in this survey, the gap between men and women is basically balanced, and the data are balanced to a certain extent.

Table 2. Descriptive Analysis of students' Reading Motivation

\begin{tabular}{llllll}
\hline & $\mathrm{N}$ & Mean & SD & Minimum & Maximum \\
\hline $\begin{array}{l}\text { 1. I do English reading because English reading is } \\
\text { very interesting. }\end{array}$ & 78 & 3.09 & 1.199 & 1 & 5 \\
$\begin{array}{l}\text { 2. I will take the initiative to do extracurricular } \\
\text { English reading. }\end{array}$ & 78 & 2.82 & 1.142 & 1 & 5 \\
$\begin{array}{l}\text { 3. I learn English reading because I want to get good } \\
\text { English grades. }\end{array}$ & 78 & 4.24 & .972 & 1 & 5 \\
$\begin{array}{l}\text { 4. I do English reading in order to have a good job in } \\
\text { the future. }\end{array}$ & 78 & 3.76 & 1.157 & 1 & 5 \\
$\begin{array}{l}\text { 5. I do English reading because of the requirements } \\
\text { of my teachers or parents. }\end{array}$ & 78 & 3.07 & 1.316 & 1 & 5 \\
$\begin{array}{l}\text { 6. I read in English in order to understand all kinds } \\
\text { of information in the world. }\end{array}$ & 78 & 3.31 & 1.162 & 1 & 5 \\
$\begin{array}{l}\text { 7. My successful understanding of an English } \\
\text { reading gives me a great sense of achievement. }\end{array}$ & 78 & 4.06 & 1.044 & 1 & 5 \\
\hline
\end{tabular}

According to Table 2, the mean value of Q1 is 3.09, and the standard deviation is 1.199, which is greater than 1, indicating a high degree of dispersion. Combined with the statistical results, it is obvious that students generally have a medium level of reading motivation in English reading. Thus it can be seen that most students are not strongly interested in English reading.

The mean value of Q2 is 2.82, which is between disagreement and uncertainty, and the standard deviation is 1.142 , indicating a high degree of dispersion. Combined with the statistical results, it can be seen that students generally have a lower medium level of reading motivation in English reading and they will not take the initiative to read in English. The average value of Q3 is 4.24, which is in the range of basic agreement. The statistical results show that most students basically agree that the purpose of English reading is to get good English grades, and they have a high level of external motivation to promote their English reading. The average value of Q4 is 3.74, indicating that most students are uncertain and basically agree in this question, while the standard deviation is 1.157 , indicating a high degree of dispersion. Combined with the statistical results, we can find that students have a strong external motivation to read English for their future work.

The average value of Q5 is 3.07, indicating that most of the students hold less positive attitude in English reading, and they are not sure about the reason why they are doing English reading, which shows the students' internal motivation is at a medium level. The mean value of Q6 is 3.31, and the standard deviation is 1.162, which is greater than 1, indicating a high degree of dispersion. Combined with the statistical results, a majority of the students hold an average attitude towards their own English reading in order to understand the information. The average value of Q7 is 4.06, implying that most students basically agree on this question. In other word, students generally agree that successfully understanding an English reading article will bring a sense of achievement, which will enhance students' internal motivation for English reading. So students' external reading motivation in this question is strong.

As can be seen from what has been discussed above, at the level of motivation, most students will not take the initiative to read English, and the reason for doing English reading is to get good English grades, to find a good 
job or at the request of parents or teachers instead of satisfying personal interests. The external motivation of students' English reading is strong, while the internal motivation is weak.

Table 3. Descriptive Analysis of students' Reading Self-efficacy

\begin{tabular}{|c|c|c|c|c|c|}
\hline & $\mathrm{N}$ & Mean & $\mathrm{SD}$ & Minimum & Maximum \\
\hline $\begin{array}{l}\text { 8. I believe I have the ability to read English } \\
\text { well. }\end{array}$ & 78 & 3.76 & 1.155 & 1 & 5 \\
\hline $\begin{array}{l}\text { 9. I believe I can overcome most of the } \\
\text { difficulties encountered in English reading. }\end{array}$ & 78 & 3.68 & 1.139 & 1 & 5 \\
\hline $\begin{array}{l}\text { 10. I never give up when I encounter difficulties } \\
\text { in English reading until the difficulties are } \\
\text { solved. }\end{array}$ & 78 & 3.42 & 1.080 & 1 & 5 \\
\hline $\begin{array}{l}\text { 11. I believe that if I persist in English reading, } \\
\text { my English reading ability will improve. }\end{array}$ & 78 & 4.07 & .928 & 1 & 5 \\
\hline $\begin{array}{l}\text { 12. I will try my best to solve the difficulties } \\
\text { encountered in English reading. }\end{array}$ & 78 & 3.87 & 1.015 & 1 & 5 \\
\hline $\begin{array}{l}\text { 13. I believe that as long as I study English } \\
\text { reading hard, my English reading ability will } \\
\text { improve. }\end{array}$ & 78 & 3.91 & 1.037 & 1 & 5 \\
\hline $\begin{array}{l}\text { 14. I think the increase in the error rate of } \\
\text { English reading will reduce my interest in } \\
\text { reading this section. }\end{array}$ & 78 & 3.42 & 1.311 & 1 & 5 \\
\hline $\begin{array}{l}\text { 15. I often feel too stressed because the students } \\
\text { around me are excellent. }\end{array}$ & 78 & 3.45 & 1.304 & 1 & 5 \\
\hline $\begin{array}{l}\text { 16. I sometimes feel depressed because my } \\
\text { reading scores don't live up to my expectations. }\end{array}$ & 78 & 3.75 & 1.213 & 1 & 5 \\
\hline
\end{tabular}

It can be seen from Table 3 that the mean values of Q8 and Q9 are 3.76 and 3.68, not reaching 4, and the standard deviations are 1.155 and 1.139 respectively, indicating a high degree of dispersion. Combined with the statistical results, most students hold an average attitude towards these two problems, indicating that the students' reading ability self-efficacy is at a medium level. The average value of Q10 is 3.42, which is between uncertainty and basic agreement. Looking at the statistical results, most of the students hold an average attitude towards this problem, while the average value of Q11 is 4.07, which is in the range of basic agreement. It shows that most students basically agree that adhering to reading will improve their reading ability. Half of the students have difficulties in reading until the problem is solved, but they agree to insist on reading to improve their reading ability. The average values of Q12 and Q13 are 3.87 and 3.91 respectively, with the average value close to 4 , which indicates the level of students' reading efficacy in these two questions is high and a large number of students have a strong sense of self-efficacy of reading efforts.

The three mean values of Q14-Q16 are 3.42, 3.45 and 3.75 respectively, which are between uncertainty and basic agreement, and the standard deviation is greater than 1, indicating a high degree of dispersion. Combined with the statistical results, students generally agree that more wrong reading questions will lead to students' interest in English reading. For Q15, students generally hold the idea that they will feel too much pressure because their surrounding students are excellent. As for Q16, students generally feel depressed because their reading results do not meet their expectations. In other words, half of the students feel their reading self-efficacy are influenced because of three factors: mastery experience, academic pressure and achievement goals.

From the above discussion, it can be seen that in terms of reading self-efficacy, the average values of students' English reading ability, persistence and effort self-efficacy are between 3-4, which are lower than 4, indicating that students' reading ability self-efficacy is not clear, reading persistence self-efficacy is contradictory, and reading effort self-efficacy is not firm. Moreover, the results show that students' self-efficacy is easily affected by mastery experience, academic pressure and achievement goals. Among the overall factors, achievement goals have the greatest influence, followed by academic pressure, and finally mastering sexual experience. 
Table 4. Descriptive Analysis of students' Reading Anxiety

\begin{tabular}{|c|c|c|c|c|c|}
\hline & $\mathrm{N}$ & Mean & SD & Minimum & Maximum \\
\hline $\begin{array}{l}\text { 17. When I answered the question of English } \\
\text { reading, the attention of my classmates made me } \\
\text { nervous. }\end{array}$ & 78 & 3.38 & 1.236 & 1 & 5 \\
\hline $\begin{array}{l}\text { 18. When I don't understand the reading } \\
\text { knowledge said by my English teacher, I will feel } \\
\text { terrible. }\end{array}$ & 78 & 3.52 & 1.092 & 1 & 5 \\
\hline $\begin{array}{l}\text { 19. When I think of answering reading questions } \\
\text { in English, I will feel anxious. }\end{array}$ & 78 & 3.62 & .947 & 1 & 5 \\
\hline $\begin{array}{l}\text { 20. I have more English reading classes than other } \\
\text { classes. }\end{array}$ & 78 & 3.08 & 1.119 & 1 & 5 \\
\hline $\begin{array}{l}\text { 21. Before class, I was upset at the thought of } \\
\text { taking an English reading class. }\end{array}$ & 78 & 3.02 & 1.173 & 1 & 5 \\
\hline $\begin{array}{l}\text { 22. It makes me feel that I take the initiative to ask } \\
\text { and answer questions in English reading class. }\end{array}$ & 78 & 3.22 & 1.063 & 1 & 5 \\
\hline $\begin{array}{l}\text { 23. I was nervous to read this section in English } \\
\text { during the exam. }\end{array}$ & 78 & 3.54 & 1.062 & 1 & 5 \\
\hline $\begin{array}{l}\text { 24. When I saw that the reading space was too } \\
\text { long during the exam, I was in a bad mood. }\end{array}$ & 78 & 3.69 & 1.158 & 1 & 5 \\
\hline $\begin{array}{l}\text { 25. I feel nervous when I do the reading questions } \\
\text { in the exam, which will affect my doing the } \\
\text { questions. }\end{array}$ & 78 & 3.54 & 1.086 & 1 & 5 \\
\hline
\end{tabular}

The mean values of Q17-Q19 are 3.38, 3.52 and 3.62 respectively, ranging from 3 to 4 , while the standard deviations of Q17-Q19 are 1.236, 1.092 and 0.947, indicating a high degree of dispersion. The statistical data manifests that most of the students have communication anxiety in reading and students' reading anxiety is at a medium level.

The mean values of Q20-Q22 are 3.08, 3.02 and 3.22 respectively, ranging from 3 to 4, while the standard deviations of Q17-Q19 are 1.119, 1.173 and 1.063. The standard deviations are large, indicating a high degree of dispersion. According to statistics, the students generally have anxiety before and during reading class and their reading anxiety is at a medium level.

The mean values of Q23-Q25 are 3.54, 3.69 and 3.54 respectively, ranging from 3 to 4, while the standard variances of Q23-Q25 are 1.062, 1.158 and 1.086 respectively, all greater than 1, showing a high degree of dispersion. Combined with statistical data, a majority of students agree that they were afraid of reading in the English test, and be upset when they saw that the reading space was too long, and some of the students would feel nervous when doing reading questions, which affected their state when doing questions. It implies that a large number of students have reading test anxiety and the level of their reading text anxiety is not high.

It can be seen from the above discussion that in terms of reading anxiety, many students have reading communication anxiety, and reading classroom anxiety also exists. And some students even have reading test anxiety, which shows that students have more aspects of reading anxiety. Among the four factors affecting reading anxiety, it is obvious that family expectations, college entrance examination pressure and classmate competition will affect students' own anxiety.

\subsection{Results and Analysis of Interview}

The interview is a semi-structured interview. The advantage of the semi-structured interview is that there are fixed questions prepared in advance and temporary additional questions according to the answers of the respondents, so as to understand the emotional factors affecting students' English reading difficulties better. The student interview mainly includes whether the students reflect, what are the factors of reflection, and what are the attribution of motivation. The outline of the student interview is as follows:

1) In which part of English reading do you lose the most points?

2) After the test, do you reflect on the reading section where you lost a lot of points and find out the reason? 
3) Which of the following options do you think should be considered in your reflection? Please rank them in order:
A. Your reading ability
B. Your effort
C. Difficulty of reading task
D. Good or bad luck
E. Physical and mental condition
F. External environment

4) What other reasons do you think influence your reading besides the lack of relevant English knowledge?

For the first question, students have a variety of answers. The score loss of each student is largely judged according to his reading level. For the second question, two students said they would analyze the reading section, and the remaining four students said they would not reflect. There are two kinds of reasons for students who will reflect: one is that they do not understand the meaning of the sentence or do not know the new words in the text, resulting in misunderstanding, the other is that they do not grasp the central meaning of the article, resulting in information analysis errors. For the third question, the six students all think that reading ability, effort and difficulty of reading tasks are very significant, which will have a great impact on their reading situation. This shows that when reflecting, students first consider the factors at the knowledge level. In addition to the students' lack of English knowledge and other related factors, there are many non knowledge factors that affect students to complete English reading tasks, but students pay less attention to non knowledge factors.

From the analysis of student interviews, students' reading loss depends on their reading level. No matter the students who actively reflect or begin to think about the reasons for the loss of reading scores under the questioning of the author, their loss of scores is due to the lack of English knowledge, which leads to the loss of reading scores. Very few students realize that the reasons at the emotional level affect students' learning. Apart from the factors at the knowledge level, some students also mentioned that emotional factors such as learning attitude, learning interest and their own mood will affect students' English reading, but students first pay attention to the impact of difficulties at the knowledge level on English reading, and pay less attention to other non knowledge barriers.

\subsection{Suggestion}

As far as students are concerned, they should be clear about their own positioning, their own learning tasks and enhance their reading motivation. The first thing students should do is to change the concept of English reading. Motivation, interest and anxiety are all psychological factors that affect students' reading. Senior high school students should establish a correct concept of performance, treat test results with a normal mind, and reduce the anxiety caused by examinations and results. The affective filtering hypothesis emphasizes the positive effect of positive affective factors, which is beneficial to the smooth input of language. Senior high school students should give full play to the positive role of emotional factors, self-shield the attacking language around them, improve their self-confidence and strengthen their self-cognition. Self-motivation is carried out in a variety of ways to play the positive role of emotional factors.

As for teachers, in the process from lesson preparation to class, they should enhance classroom interaction, make teaching activities diversified and interesting, and increase the diversity and interest of teaching content, so as to attract students' attention and interest. Guide students to carry out meaningful learning, so that students take the initiative to let their emotions and cognition participate in learning activities. Teachers should constantly improve their emotional control ability, hide negative emotions such as fatigue and depression, put their own positive emotions into the teaching process, and apply positive enthusiasm and healthy positive emotions to teaching.

For schools, schools should offer mental health courses and ensure that the courses are implemented as scheduled. Hire a professional psychological counselor and set up a psychological counseling room. Finally, the school carries on educational psychology training for teachers, teachers of all subjects need to understand psychology, on the one hand, in order to give better play to the influence of teachers on students, on the other hand, so that teachers can find students' psychological problems in time. Parents should pay attention not only to students' grades, but also to their physical and mental health. Parents should learn to ask for help. Most senior high school students are unwilling to share their study and life with their parents. At this time, it is necessary for parents to contact schools and teachers in time, connect family and school education, form joint efforts in education, and make joint efforts to pay attention to students' physical and mental health.

\section{Conclusion}

After the study, it is found that affective factors to a certain degree have a negative impact on senior high school students' English reading. The questionnaire used in this study investigated students' motivation, self-efficacy and anxiety, supplemented by student interviews, and found that reading anxiety among senior high school 
students is fairly common. Furthermore, students' internal motivation for English reading is weak and their sense of reading self-efficacy is not clear.

The study investigates the current situation of the influence of emotional factors on senior high school students with low English reading ability in a school from three aspects: motivation, self-efficacy and anxiety. This paper analyzes the causes of senior high school students' emotional factors on English reading ability and puts forward corresponding suggestions to improve them, which basically achieves the expected research purpose. However, due to time constraints and the author's own limited level, this study has the following shortcomings, first, there are few sample schools in this study, because this study is a case study, so there is only one school under research. Second, the subject selected in this study is only one grade in the second year of senior high school. Third, there are still deficiencies in questionnaire design and research dimensions. Emotional factor is a large category, but the author only studies the three influential factors. Fourth, there is no interview or survey of teachers in this study, and the research suggestions put forward are lack of teachers' suggestions for improvement.

In the future research, researchers can appropriately expand the scope of research and choose more diversified schools to make. The research is more representative in the region. In the choice of research objects, students of other senior high school grades can be selected for research. It makes the research more representative. The design and compilation of the questionnaire should be more scientific.

\section{References}

Alqarni, F. (2015). Collaborative Strategic Reading to Enhance Learners' Reading Comprehension in English as a Foreign Language. Academic Journal of Interdisciplinary Studies, 4(1), 161-166. https://doi.org/10.5901/mjss.2015.v4n1p161

Arnold, J. (1999). Affect in language learning. Cambridge: Cambridge University Press.

Barfield, A. (1999). In Other Words: How Learners Construct Reading Difficulties. Literacy Across Cultures.

Brown, H. D. (2009). Principles of Language Learning and Teaching. Foreign Language Teaching and Research Press.

Cui Wenli, \& Feng Lichun. (2008). On the Cultural Influences on the Reading of English. Journal of Hebei Normal University (Education Science Edition), (4), 128-130.

Duan Hongying, \& Wu Biyu. (2012). An interpretation of the Teaching of English Reading Comprehension from the Perspective of Cohesion Theory. Education Research Monthly, (6), 101-103.

Fan Rongping, \& Fu Rui. (2012). The Present Situation and Training Strategies of Middle School Students' English Reading Ability. Teaching and Management, (30), 95-96.

Gardner, H., \& Lambert, W. E. (1972). Attitudes and Motivation in Second Language. Rowley, Mass: Newbury House.

Hao Yujun. (2011). The Influence of Senior High School Students' Thinking Style on English Reading comprehension. Teaching and Management, (30), 117-118.

Horwitz, E. K., Horwitz, M. B. H., \& Cope, J. (1986). Foreign Language Classroom Anxiety. Modern Language Journal, (2), 125-132. https://doi.org/10.1111/j.1540-4781.1986.tb05256.x

Hu Chundong. (1999). On English Reading. Nanning: Guangxi Education Press.

Krashen, S. D. (1985). The Input Hypothesis: Issues and Implications. London: Longman.

Meng Bin, \& Chen Ting. (2011). Affective factors and English Teaching. Journal of Jiangxi Institute of Education, 32(2), 92-94.

O’Malley, J. M., \& Chamot, A. (1990). Learning Strategies in Second Language Acquisition. Cambridge: Cambridge University Press. https://doi.org/10.1017/CBO9781139524490

Rogers, C. (1994). Freedom to Learn. New York: Merrill.

Su Aiqiong. (2010). The Application of Functional Sentence Theory in English Reading Comprehension. Teaching and Management, (12), 65-66.

Torgesen, J. K. (2002). The Prevention of Reading Difficulties. Journal of School Psychology, 40(1), 7-26. https://doi.org/10.1016/S0022-4405(01)00092-9 
Zhang Huihui. (2014). A study on the Problem of English Reading Ability Disorder. Foreign Language Teaching, (8), 30-32.

Zhang Zhengdong. (1985). Affective Factors in Foreign Language Teaching. Journal of Southwest Normal University (Humanities and Social Sciences ed.), (2), 127-131.

\section{Copyrights}

Copyright for this article is retained by the author(s), with first publication rights granted to the journal.

This is an open-access article distributed under the terms and conditions of the Creative Commons Attribution license (http://creativecommons.org/licenses/by/4.0/). 